\title{
Developmental psychology approach of autism
}

\author{
Hervé Segond* \\ Laboratoire de Psychologie des Cognitions, LPC EA 4440, Faculté de Psychologie, Université de Strasbourg, 12 rue Goethe - 67000 Strasbourg, France
}

Since the diagnosis and tracking of autism has been based on a clinical approach, we aim to work through, in this short communicationtype article, three main questions around the methodological and theoretical principles of the psychological approach of people with this neurodevelopmental disease.

If autism is indeed a neurological disease with (at least partially) a complicated genetic background, what can psychologists do to help autistic patients?

Difficulties in cases of autism are present in both the side of the autistic people themselves in their perception and understanding of their physical and social environment, and on the side of their social environment (familial and professional), who are in charge of helping them to develop their autonomy.

Every psychologist caring for patients must rely on the subjectivity of these persons, in accordance with the deontological code of our profession. Knowing the specificities of autists' learning processes, understanding and giving sense to their atypical behavior is necessary, not only to achieve this respect of their subjectivity, but also for the diagnosis of the early manifestations of autism (before 3 years), and then for proposing the best possible environmental adaptations based on scientific research (objectively evaluated and proved) and relating to integrative data from different fields of knowledge and approaches: rigorous clinical observation in psychopathology, neuroscience and molecular biology, always with regard to the individual singularity, its needs, expectations and refusals. From this perspective, taking more into account these last years the testimonies of autistic adults themselves allowed to reconsider our own definition of autism ( $c f$. DSM-5, 2013: edited by American Psychiatric Association; and ICD11, 2018; International Classifications of Diseases, edited by World Health Organization).

Thus, for autistic people, the official diagnosis criteria (communication and interaction troubles; restricted and stereotypical behaviors) are the secondary expression of more primary difficulties: emotional regulation disability, atypical ways of processing information, and alterations of sensory systems [1]

These troubles became central among the main models of explanation in autistic syndrome, and in the multidisciplinary psychotherapy approach of autistic people focused on their emotional and sensorimotor reactions (e.g. meaning of individual stereotypes, interest and emotional reactions towards stimuli according to sensory modalities), their atypical perceptual functioning, the necessary temporal adjustment of the psychologist to their own tempo (i.e. generally by slowing down his movements, gesture, actions and speech), activation of the imitate/being imitated loop - key for starting interaction -, and commentaries showing comprehension and empathy to enhance affective accordance and trust (i.e. "intersubjectivity"; affective accordance between the person with ASD and the therapist).

\section{What is the contemporary scientific vision (idea) of the psychological components in autism?}

Autism shows different forms of expression designated through the notion of Autistic Spectrum Disorders, according to four clinical indicators for diagnosis: intelligence (presence or absence of mental retardation), language (presence or absence), comorbidity, and severity.

Disorders concern a big set of social and non-social domains, and in particular, perception (including sensoriality and information processing), for which we know the behavioral cues sustained by data from cerebral functional imagery showing differences between autist and neurotypical subjects concerning connectivity between perceptual areas and other cerebral functions.

Prototypical autism, without mental retardation, represents the most homogeneous category of autism; they are most of the time nonverbal in pre-scholar age, and language appears at about 4-5 years but in a nonfunctional way for communication. From this age, the autistic child can be evaluated with intelligence scales, often showing a normal nonverbal intelligence at about 5 years.

Concerning sensory and perceptual disorders in autism, first, autistic people have difficulties to realize synthesis and multisensory integration of perceived stimulations (eg. visual and auditory), a necessary capacity for the comprehension and efficient usage of information from the environment.

The sensory reactions of autists can be explained by a disorder in sensory information processing due to a deficit of sensory modulation as a result of an alteration of filtration systems of sensory flows. These disorders are set in three categories: hyper-reactivity, hypo-reactivity, and search of stimulation for Ben Sasson et al. [2], hyper-sensitivity, hypo-sensitivity, and mono-sensory processing for Bogdaschina [3].

The functioning of autistic subjects reveals an atypical usage of sensorimotor systems: they maximize the effects of archaic systems for each sensory modality at the cost of developing exploration strategy that would allow elaborating a representation of the explored source of stimulation. Moreover, autistic people prefer proximal sensory modalities (i.e. touch, vestibular perceptions) at the cost of distal ones (i.e. vison and audition [4-6]).

They also show some hyper functioning of low level perceptual processing (i.e. local aspects, details), besides normal capabilities for

*Correspondence to: Hervé Segond, Laboratoire de Psychologie des Cognitions, LPC EA 4440, Faculté de Psychologie, Université de Strasbourg, 12 rue Goethe-67000 Strasbourg, France, E-mail: herve.segond@unistra.fr

Received: August 29, 2018; Accepted: September 10, 2018; Published: September 13, 2018 
global aspects of information processing. Their perceptual activities are functionally autonomous about "top-down" processing influences [7]. Our brain interprets what we perceive according to our experiences and learning; these influences are optional for autists but obligatory for us - $c f$. perceptual illusions). This phenomenon is mostly responsible of extraordinary drawing abilities among some "autistic savants", very often mediatized.

In addition, people with ASD have difficulties processing and integrating physical and biological moving stimuli [8], showing, consequently, a particular way of visually exploring human faces, focusing on the bottom part of faces instead of the upper part including eyes as in usual communication. Yet, we know the importance of movement in early visual perceptions for perceptual organization in babies and to perceive objects' properties (i.e. unity, permanence).

We can easily understand the relationship between these sensory disorders and alterations of social interaction and communication, knowing the role of sensoriality in the early, normal development of interactional and social competencies in infants, in the frame of developing intersubjectivity in association with their early motorperceptual and emotional abilities.

This synthetic picture of sensory and perceptual particularities of people with ASD must be completed by analyzing the functions of repetitive behaviors (stereotypies) for the subject. Stereotypies differ between subjects and they do not have the same value or the same function. Some are the consequence of a lack of stimulation, while others show the attention towards stimulation. For example, eyes blinking lead to a reduction in the quantity of information brought by the optic flow, and consequently allows the autistic subject to maintain his attention on some interesting visual target. Understanding the individual characteristics and function of stereotypies is fundamental to determine the interests of the autistic child and one of the possible indications relative to his intelligence in front of various situations and objects.

The idea here is to work with an autistic child in the manner we would with any other normal child, but according to his interests and specificities. This principle is in fact the one that is usually followed in the frame of normal development and education. Our adaptation to the autistic difference and therapeutic approaches must be respectful to the rights of a human child; the rights for equality. Autistic children deserve normal postulate of education, which implies that they should have access to material according to their interests, as a neurotypical child, and to regulated interactions, such as in kindergarten.

\section{Which therapies, based on the psychological approach, exist and what are their advantages and disadvantages?}

I previously spoke about a plural multidisciplinary psychotherapy approach of autistic people. Indeed, I would say that psychological care of autism is a paradigmatic example of the necessary multidisciplinary approach that must be run to propose the most adequate help, based on validated scientific data, not only to people with ASD, considering their expectations, needs, interests and refusals, but also their families, in interaction with professionals and institutions. In fact, disadvantages exist only in cases of exclusive use of theoretical approachs to understand particularities of autistic problematics, or even worse, such as the method of taking care.

Globally, our understanding of the functioning of autistic people, showing an atypical usage of sensorimotor systems, benefits from neuropsychology, neurophysiology, developmental cognitive psychology and psychodynamic approach (psychanalysis).
Similarly, autistic people themselves can potentially benefit from different psychological approaches whose purposes are different and complementary. Thus, developmental psychological and cognitive approaches allow us to evaluate atypical sensory and perceptual functioning, disorders in imitation, language, empathy, emotional expression and understanding, social communication, and to analyze individual stereotypies functions. Our theoretical and methodological approach in Developmental Psychology proposes care based on sensory therapies using a Snoezelen environment (favoring both relaxation and stimulation in an adapted way according to the subject's specific needs; [9], focused on intersubjectivity development, well-being, and reactivity to sensory environments according to its characteristics (solicited sensory modality - i.e. proximal vs. distal - mono or multimodal nature of stimuli). This individualized and contextualized methodological approach of autist cognition allows us to reach the subjectivity of these autistic people (even in case of associated mental retardation and absence of language) from their atypical embodiment (lived experience and corporal functioning [10]) via each individual sensory profile, and consequently to also support the development with time of social communicational and interactional competencies sustained by increased sensory integration abilities.

Neuropsychological approaches are necessary to evaluate disorders such as relative to attention (excess or default), cerebral modulation, flow information processing, executive functions, and habituation to novelty ( $c f$. cerebral hyper-reactivity of children to novelty/change, showed by Gomot et al. [11]), sensorimotor coupling, sensory and sensorimotor systems.

The Psychanalysis approach has been intensely criticized due to a lack of rigorous methodology and the refusal of any mean of evaluation of the benefits of psychanalytic therapies. Yet, such evaluations must be integrate part of the therapeutic and scientific process. Nevertheless, the contribution of psycho-dynamic is important in the frame of a multidisciplinary approach of autism in order, for example, to sustain emotional interactions between the autistic child and his parents, to identify and sustain psychic movements of parents and professionals by analyzing transference and countertransference movements between the autist and his social environment.

With the goal of getting rid of psychanalysis, psycho-educative approaches using behaviorist methods (Applied Behavioral Analysis) from North America (based on Lovaas program from 70') became at one point very popular (e.g. Canada, France). But this time has ended since their efficacy was clearly overestimated, as it was revealed by the Effective Health Care Program's report published by the American Pediatric Academy in 2011. In fact, efficacy of ABA on language, cognitive and educative evolution, adaptation and symptoms severity of ASD appears weak. Moreover, strict application of such behaviorist programs, as early as possible (sometimes from the age of one) and as long as possible ( 40 hours/week) is not far from lucrative objectives and gives stressing educative objectives to parents of ASD kids. Nevertheless, in a less extremist way to consider, here also, the possible contribution of such approach, ABA proposes some interesting tools to help ASD people by structuring space and time ( $c f$. Treatment and Education of Autistic and related Communication Handicapped Children - TEACCH - psycho-educative program), or with methods of augmentative and alternative communication (by visual or gestural means, such as PECS - Picture Exchange System).

Finally, the systemic approach allows for identifying, analyzing, and raising awareness about pathological and paradoxical communication and interactions inside a family, in any medico-social institution, or 
between a family and institutions or schools, and provides insight into ways of changing.

In conclusion, the great vulnerability of people with autism (especially in cases of deep associated mental retardation) in terms of their bodily and psychic integrity, and their extreme sensitivity to their sensory and social environment, imperatively require an adapted knowledge of the specificities of their bodily experience and functioning, of which singular and qualitatively different nature must be studied precisely. The heterogeneity of the problem of these subjects necessarily implies an individualized and contextualized approach to their embodied cognition, which should be systematically supported.

\section{References}

1. Chamak B, Bonniau B, Jaunay E, Cohen D (2008) What can we learn about autism from autistic persons? Psychother Psychosom 77: 271-279. [Crossref]

2. Ben-Sasson A, Hen L, Fluss R, Cermak SA, Engel-Yegger B, et al. (2009) A MetaAnalysis of Sensory Modulation Symptoms in Individuals with Autism Spectrum Disorders. J Autism Dev Disord 39: 1-11. [Crossref]

3. Bogdaschina O (2012) Questions sensorielles et perceptives dans l'autisme et le syndrome d'Asperger : des expériences sensorielles différentes, des mondes perceptifs différents. Grasse : AFD - Autisme France diffusion.
4. Bellusso P, Maumy-Bertrand M, Desnos Y, Segond H (2014) Intérêts de la psychothérapie à médiation sensorielle dans le cadre de la prise en charge des troubles de la relation et de la communication chez des enfants autistes sévèrement déficitaires II ; Illustration clinique. Neuropsychiatrie de l'Enfance et de l'Adolescence 62: 95-101.

5. Bellusso P, Desnos Y, Segond H (2014) Intérêts de la psychothérapie à médiation sensorielle dans le cadre de la prise en charge des troubles de la relation et de la communication chez des enfants autistes sévèrement déficitaires I; Introduction aux applications cliniques. Neuropsychiatrie de l'Enfance et de l'Adolescence 62: 90-94.

6. Segond H (2015) Le Toucher en Développement : Latéralité, Cécité, Autisme. Des activités perceptives au soin. Sarrebruck : Editions Universitaires Européennes.

7. Caron MJ, Mottron L, Berthiaume C, Dawson M (2006) Cognitive mechanisms, specificity and neural underpinnings of visuospatial peaks in autism. Brain 129: 17891802.

8. Tardif C, Latzko L, Arciszewski T, Gepner B (2017) Reducing Information's Speed Improves Verbal Cognition and Behavior in Autism: A 2-Cases Report. Pediatrics 139: e20154207. [Crossref]

9. Hulsegge J, Verheul A (1988) Snoezelen: Another World. Londres: Rompa.

10. Varela FJ, Thompson E, Rosch E (1991) The Embodied Mind - Cognitive Science and Human Experience. Boston, MA: MIT Press.

11. Gomot M, Blanc R, Clery H, Roux S, Barthélémy C, et al. (2010) Electrophysiological biomarkers of hyper-reactivity to change in autism. J Autism Dev Disord 41: 705-714.

Copyright: (C2018 Segond H. This is an open-access article distributed under the terms of the Creative Commons Attribution License, which permits unrestricted use, distribution, and reproduction in any medium, provided the original author and source are credited. 